University of South Carolina

Scholar Commons

4-1992

\title{
Scholarly Behaviors of Physical Education Methods Teacher Educators in Ohio
}

Murrary F. Mitchell

University of South Carolina - Columbia, mmitchel@mailbox.sc.edu

Follow this and additional works at: https://scholarcommons.sc.edu/pedu_facpub

Part of the Education Commons

\section{Publication Info}

Published in Journal of Teaching in Physical Education, Volume 11, Issue 3, 1992, pages 303-314. http://journals.humankinetics.com/jtpe-contents (C) 1992 by Human Kinetics Publishers, Inc.

This Article is brought to you by the Physical Education, Department of at Scholar Commons. It has been accepted for inclusion in Faculty Publications by an authorized administrator of Scholar Commons. For more information, please contact digres@mailbox.sc.edu. 


\title{
Scholarly Behaviors of Physical Education Methods Teacher Educators in Ohio
}

\author{
Murray F. Mitchell \\ Rutgers University
}

This study focused on the behavior of a proportional, stratified random sample of 40 physical education methods teacher educators (PEMTEs) in the state of Ohio, or more specifically, on the professional implications of their scholarly behaviors. The focal questions addressed were (a) how do PEMTEs meet their responsibility to stay current in their professional areas, and (b) what are the professional implications of these efforts? Four specific behaviors were examined as evidence of scholarly behaviors: (a) reading professional journals, (b) writing for publication, (c) attendance at professional conferences, and (d) active involvement in research. Findings were then contrasted to findings from previous studies of physical educators, education professors, and university professors. PEMTEs in Ohio tend to read the professional literature related to physical education without attending to the literature in the broader realm of education. Few of the PEMTEs in Ohio write for publication or are actively involved with research-behaviors shared with other physical educators, education professors, and many university professors. PEMTEs appear to attend more state and national meetings than do other physical educators or other university professors. The extent of involvement at such conferences, however, is unknown. Implications of the behaviors described are discussed, and conclusions are drawn on the basis of the reported data.

Physical education methods teacher educators (PEMTEs) play an important role in the development of physical education teachers. At the very least, PEMTEs serve as gatekeepers to the profession, controlling who will pass through the methods courses to student teach and, subsequently, acquire certification. PEMTEs designate particular knowledge, skills, attitudes, and values as appropriate by selecting learning experiences for aspiring teachers. Hence, it would seem crucial that such professional mediation be tempered with a current and informed stance toward the exploding knowledge base within both physical education as content and teacher education as process. The purpose of this paper is to address the extent to which PEMTEs demonstrate scholarly behaviors consistent with their roles as members of the university professoriate. In the

M. F. Mitchell is with the Department of Exercise Science and Sport Studies at Rutgers University, 109 Loree Gymnasium, P.O. Box 270, New Brunswick, NJ 089030270 . 
context of this paper, scholarly behavior refers to the ways PEMTEs meet their responsibility to stay current in their professional areas.

Selecting indicators of exactly how PEMTEs stay current is problematic. These professors occupy a precarious position in academe, with role expectations from the college or university and from the public schools - two role identities that present a role dilemma for teacher educators (Ducharme \& Agne, 1982; Haberman, 1981; Williamson, 1990). Wisniewski and Ducharme (1989) identified the significance of the university's responsibilities, stating that "scholarship is the sine qua non of the professorial life"' (p. 150). They went on to present their value position as follows: "The education professoriate, first and foremost, must be characterized by professors who are active producers and consumers of scholarship" (Wisniewski \& Ducharme, 1989, p. 152). Views of the role of scholarship for physical educators are similar. Silverman (1987), for example, suggested that at least one goal for physical education scholars should be to " train the future generation of researchers and practitioners to appropriately plan, understand, and value the research enterprise" (p. 69).

Responsibilities as a teacher, on the other hand, tend not to involve these same expectations for the production and consumption of knowledge. Although it is true that a teacher should be teaching material that is current, the focus is more on the process of instructional delivery. The demonstration of pedagogical expertise requires a different set of skills and knowledge than does the demonstration of scholarship productivity.

Related to the different role identities just described are differences with regard to what is defined as knowledge. There are different types of knowledge. At the very least, one may identify research-based or scientific knowledge, and personal or practical knowledge. Feiman-Nemser and Floden (1986) suggested that because a higher value is typically placed on scientific knowledge, other types of knowledge are often devalued. This stems from a limited, rather than general, orientation. Feiman-Nemser and Floden went on to argue that neither of these two forms of knowledge are more effective; rather, they are different. Hence, the valuation of a particular type of knowledge must be relative to intended uses. Scientific knowledge, for example, might be of higher value when intended uses include fueling future research studies and/or generating principles. In contrast, personal or practical knowledge may be of greater value to the practitioner seeking understanding of the unique nuances of a particular job or setting. Hence, what might be identified as appropriate knowledge for PEMTEs may differ for different individuals in different settings.

The selection of possible strategies for knowledge acquisition is dependent upon the individual's approach to his or her role. Researchers typically acquire knowledge by doing research, reading professional journals, and attending professional conferences (Burch, 1989). In contrast, teachers acquire knowledge through experiences related to teaching physical education (e.g., coaching, participating in athletics), through participating in physical education classes as a student, from colleagues, and simply from practice (Earls, 1981). This view of knowledge acquisition for practice is not unique to physical education. Rein and White (1981) argued that, for social work, "knowledge necessary for practice must come from practice itself to a great extent', (p. 22). So, the ways PEMTEs acquire knowledge for their practice may depend upon how they perceive their role. 
For this study, the role identity that meets the demands of the university, rather than the demands of the public schools, was selected; the relevant knowledge was identified as research-based or scientific knowledge, rather than personal or practical knowledge; and strategies for knowledge acquisition consistent with researchers, rather than with teachers, were selected for study. These indicators were selected because they are consistent with data collected in previous studies of university professors (Carnegie Foundation, 1985; Eckert \& Williams, 1972; Freeman, 1977; Jacobson, 1985; Ladd \& Lipset, 1976), education faculty (Burch, 1989; Ducharme \& Agne, 1982; Raths, 1985), and physical educators (Metzler \& Freedman, 1985; Scott, 1986) with regard to examining indicators of scholarly behavior. Data from previous studies are presented and contrasted with findings from the current study to facilitate a comparison of the extent to which PEMTEs demonstrate similarities to and differences from other university professors.

The questions addressed were (a) how do PEMTEs meet the role responsibility to stay current in their professional areas, and (b) what are the professional implications of these efforts? Four specific behaviors were examined as evidence of scholarly behavior: (a) professional journal reading, (b) writing for publication, (c) attendance at professional conferences, and (d) active involvement in research.

\section{Methods}

\section{Subjects and Data Collection}

To qualify as subjects, individuals had to be responsible for at least one course designated as a "methods of teaching physical education" course at an accredited program in the state of Ohio. Such a course was distinguished from instruction courses in basic skills (e.g., as softball) in which some attention was devoted to instructional concerns. Generic " methods of teaching" courses offered by a department of education were also identified as a separate type of methods course not within the realm of the definition in the present investigation.

A population of 85 PEMTEs was identified as the pool of potential subjects for study. These subjects were from 35 different institutions. That is, schools of different sizes and missions exert forces on faculty to perform their duties in different ways. The Carnegie Foundation (1976) provided a classification system for studies of higher education in which schools are divided on the basis of such factors as the amount of external financial support for research, number and types of degrees awarded, and areas of study available. Six categories within the Carnegie classification system were represented in this study: Research Universities, Doctorate-Granting Universities I, Doctorate-Granting Universities II, Comprehensive Universities and Colleges I-Public, Comprehensive Universities and Colleges I-Private, and Liberal Arts Colleges II. The distribution of subjects by gender and institution type appears in Table 1.

Subjects were stratified on the basis of the Carnegie categories. The number of subjects represented in the selected sample were based on the proportions of PEMTEs in each Carnegie category in the state. PEMTEs were alphabetized within strata (regardless of institutional affiliation), and a table of random numbers was consulted to select subjects. A proportional, stratified, random sample of 40 PEMTEs, representing 27 different institutions, was selected for study. ${ }^{1}$

The data for this study were collected as part of a larger investigation in the spring of 1988 through a focused interview (Mitchell, 1988). Data on teaching, 


\section{Table 1}

\section{Sample Distribution by Gender and Institution Type}

Research Universities

Doctorate-Granting Universities I

Doctorate-Granting Universities II

Comprehensive Universities \& Colleges I-Public

Comprehensive Universities \& Colleges I-Private

Liberal Arts Colleges II

Totals

$\begin{array}{rrrr}1 & 3 & 1 & 4 \\ 2 & 2 & 2 & 4 \\ 3 & 2 & 3 & 5 \\ 3 & 3 & 3 & 6 \\ 6 & 3 & 3 & 6 \\ 12 & 7 & 8 & 15 \\ 27 & 20 & 20 & 40\end{array}$

research, service, coaching and/or other ${ }^{2}$ responsibilities were collected for each subject as a portion of the overall description of job performance. Personal, faceto-face interviews took place at the subject's convenience. The time and location for the interviews were agreed upon in advance, and every attempt was made to fit into the subjects' schedules. Individuals were informed that the interview would take approximately 1 hour to complete. In fact, interviews ranged from $50 \mathrm{~min}$ to $133 \mathrm{~min}$. The mean time for interviews was $90 \mathrm{~min}$.

Relationships within the data were revealed through frequency counts and analysis of variance, with subsequent post hoc analyses where indicated using the Scheffe comparison. An alpha of .05 was used as the critical level for determining statistical significance for the analysis of variance and post hoc comparisons. This level was chosen because it has been identified as a common criterion for evaluating similar research outcomes (Minium, 1978) and because there was a precedent with comparable physical education data (Scott, 1986).

Analyses were performed on a subject-by-subject, item-by-item basis. The purpose of these analyses was to identify possible patterns among subjects in age (5 levels), gender (2 levels), institution type (6 levels), and rank (6 levels); these variables were identified throughout the reviewed literature as potentially significant.

The nature of the sampling procedure, based on related research and the composition of institution types in the state of Ohio, yielded an unfortunate side effect. The small cell sizes and the large number of statistical comparisons increase the risk of errors when attempting to draw inferences to larger populations. Hence, caution must be exercised when interpreting the results in this study. Future studies that add to the size of the pool of subjects providing responses to similar probes would enhance the value of the following information. Moreover, it is possible that future studies would be enhanced through an alternative grouping of institution types to facilitate larger cell sizes and to be more inclusive of different institutional types in which comparable demands are placed on faculty.

\section{Results and Discussion}

Results will be presented under the headings of the four possible responses to the question of how physical education methods teacher educators (PEMTEs) 
meet their responsibility to stay current in their professional area. Findings from studies of other samples of university professors (Carnegie Foundation, 1985; Eckert \& Williams, 1972; Freeman, 1977; Jacobson, 1985; Ladd \& Lipset, 1976), education faculty (Burch, 1989; Ducharme \& Agne, 1982; Raths, 1985), and physical educators (Metzler \& Freedman, 1985; Scott, 1986) are reported and contrasted where appropriate.

\section{Reading Professional Journals}

The PEMTEs were asked to identify the professional periodicals that they read. Their responses are contrasted with findings published by Metzler and Freedman (1985) in Table 2. Journal of Physical Education, Recreation \& Dance (JOPERD) was the most frequently identified professional publication. The next most popular was Future Focus, a publication of the Ohio Alliance for Health, Physical Education, Recreation and Dance. Research Quarterly for Exercise and Sport $(R Q E S)$ was less popular with PEMTEs in Ohio than it was with Metzler and Freedman's sample of physical education faculty, as is illustrated in Table 2. Kappan, Strategies, and the Journal of Teaching in Physical Education (JTPE) were each identified by $20 \%$ of the PEMTEs in Ohio. With notable exceptions for the state publication and $R Q E S$, these numbers were reflected in Metzler and Freedman's study. ${ }^{3}$ A total of 88 journals were identified by PEMTEs in Ohio, but, other than the periodicals just mentioned, none were cited by more than 1 or 2 subjects.

Nearly $80 \%$ of the subjects in each study did not regularly read the current research reported in JTPE. The attention paid to the larger arena of education research was also minimal. Only $25 \%$ of the PEMTEs reported regularly reading at least one of three journals that address issues in education more broadly: Journal of Educational Research, Kappan, and Journal of Teacher Education. The attention paid to sport-specific and coaching magazines was also low.

The relationship between journals and variables of age, gender, institution type, and rank yielded two significant interactions. It appeared that JOPERD $(F=$ $3.171, p=.0252$ ) was read more commonly in all but the eldest (60-69 years) age group. ${ }^{4}$ However, there were no significant results from the Scheffe post hoc

\section{Table 2}

\section{Professional Journal Reading}

\begin{tabular}{lcc}
\hline & & \\
JOPERD & $85 \%$ & $85 \%$ \\
Future Focus & $37.5 \%$ & $18.1 \%$ \\
RQES & $27.5 \%$ & $47.4 \%$ \\
JTPE & $20 \%$ & $18.1 \%$ \\
Strategies & $20 \%$ & \\
Kappan & $20 \%$ & $15.8 \%$
\end{tabular}

${ }^{\mathrm{a}}$ Data from Metzler and Freedman (1985). 
analyses contrasting the age groups with each other. Another relationship was highlighted in the comparison between institutional types and the reading of Kappan ( $F=2.73, p=.0354)$. Although there were no significant findings from the Scheffe post hoc analyses, this journal appeared to be more popular in all but the Doctorate Granting Universities II and the Comprehensive Universities and Colleges 1-Private. ${ }^{5}$

To summarize, PEMTEs in Ohio who regularly read the professional literature appeared to demonstrate a preference for literature addressing the physical education aspect of their role. Literature related to the broader arena of education did not appear to attract much attention. One avenue toward such awareness is through writing for publication.

\section{Writing for Publication}

Writing for publication is a task related to but different from performing research. In studies across faculties, the number of professors who have never published an article has been reported as about 30\% (Carnegie Foundation, 1985; Ladd \& Lipset, 1976). Furthermore, the number of faculty members who have never written or edited a book or monograph has been reported as high as $59 \%$ (Carnegie Foundation, 1985). Percentages of nonparticipation in publishing activities as reported by gender show that women have been less active than their male counterparts (Freeman, 1977). Comparisons among faculty and by gender are reported in Table 3.

Ducharme and Agne (1982) and Burch (1989) reported comparisons between samples of education faculty and noneducation faculty with regard to publication behaviors. Illustrated in Table 4, these reports show striking similarities between both types of faculty. These data would seem to confirm the observation that the bulk of published research in this country tends to be the result of the labor of only a small portion of the faculty.

The picture within physical education faculties appears to be similar to other faculties. Ninety percent of the subjects in Ohio had not published within the preceding 2 years. Furthermore, the majority of subjects reported that they were not currently involved with research that was expected to lead to publication.

Table 3

Gender Differences in Writing for Publication

$\frac{\text { University professors }}{\mathrm{All}^{\mathrm{a}} \quad \text { Females }^{\mathrm{b}} \text { Males }^{\mathrm{b}}} \quad \frac{\text { Physical educators }}{\mathrm{All}^{\mathrm{C}}}$

\begin{tabular}{lcccc}
$\begin{array}{l}\text { Never published } \\
\begin{array}{c}\text { Never written or edited } \\
\text { a book or monograph }\end{array}\end{array}$ & $30 \%$ & $38 \%$ & $15 \%$ & $33.9 \%$ \\
\hline
\end{tabular}

\footnotetext{
${ }^{a}$ Data from the Carnegie Foundation for the Advancement of Teaching (1985).

bata from Freeman (1977).

${ }^{\mathrm{C}}$ Data from Mitchell (1988).
} 
Table 4

A Comparison of Faculty Career Publications

\begin{tabular}{llllr}
\hline & \multicolumn{4}{c}{ Number of journal articles } \\
\cline { 2 - 5 } Faculty & 0 & $1-5$ & $6-19$ & $20+$ \\
\hline \multirow{2}{*}{ SCDE } & 24 & 46 & 18 & 10 \\
Non-SCDE & 23 & 54 & 21 & 2 \\
\hline
\end{tabular}

Note. Data from Burch (1989). SCDE = Schools, Colleges, and Departments of Education.

One subject in the remaining $10 \%$ had published five refereed and two nonrefereed works in the preceding 2 years. There were no statistically significant differences with regard to writing for publication on the basis of age $(F=2.051, p=.1085)$, gender $(F=.096, p=.7578)$, institution type $(F=2.305, p=.066)$, or $\operatorname{rank}(F=1.362$, $p=.263){ }^{6}$

Metzler and Freedman (1985) reported a mean of 3.7 refereed and 1.9 nonrefereed publications across careers for the subjects in their sample of physical education faculty (p. 126). Only 35\% of the subjects in Metzler and Freedman's sample had one or more refereed publications, and $6 \%$ of the subjects had six or more refereed publications in their careers. In Scott's (1986) study of physical education faculty, $33.9 \%$ of subjects reported that they had never had an article published in academic or professional journals. Only $36.9 \%$ had ever had work published as a book or monograph or had edited a book (Scott, 1986, p. 91).

These data suggest that PEMTEs are comparable to other physical educators, to other education professors, and to other university professors with regard to writing for publication; only a small proportion of PEMTEs write for publication. As a group, successes, failures, concerns, insights, and/or strategies for professional practice are not publicly discussed. Sharing expertise is not limited to writing for publications. Another possible demonstration of scholarly behavior is attending professional conferences.

\section{Attendance at Professional Conferences}

The PEMTEs were asked to identify meetings they had attended over the past 2 years. The strongest and most consistent support appeared to be for regional professional meetings specific to physical education. Attendance at two or more of these meetings over the past 2 years was noted by $47.5 \%$ of the subjects. An additional $22.5 \%$ of the subjects had attended one such meeting. The next strongest support was given to national physical education meetings. Although $45 \%$ of the subjects had not attended any such meetings over the past 2 years, $27.5 \%$ had attended one meeting, and another $27.5 \%$ had attended two or more meetings. No other professional organization meetings attracted as much attention. The statistical relationships with regard to professional conference attendance on the basis of age (national meeting attendance, $F=2.215, p=$ .0874 ; regional meeting attendance, $F=1.989, p=.1178$ ), institution type (national meeting attendance, $F=2.117, p=.0873$; regional meeting attendance, $F=2.291$, 
$p=.0674$ ), and rank (national meeting attendance, $F=1.235, p=.3146$; regional meeting attendance, $F=412, p=.8373$ ) did not result in statistically significant findings. ${ }^{7}$ The statistical analysis of gender (national meeting attendance, $F=$ $.3885, p=.5372$; regional meeting attendance, $F=4.56, p=.0392$ ) showed that women were more likely to attend regional meetings than were men. ${ }^{8}$

Other studies of professional meeting attendance identified less active patterns than can be seen with the PEMTEs in Ohio. Jacobson (1985) noted that the majority of university professors in his study had not attended any professional meetings in the previous year. Scott (1986) found that $30.9 \%$ of his physical education subjects had attended only one professional meeting in the previous year. In Ohio, $70 \%$ of the PEMTEs interviewed reported attending one or more professional meetings over the past 2 years.

PEMTEs appeared to attend more professional meetings than general physical educators or general university faculty. Unfortunately, however, the data do not provide enough information to determine whether or not attendance patterns are consistently high. Furthermore, the ways and extent to which PEMTEs actually participate at conferences is difficult to determine.

\section{Active Involvement in Research}

The amount of time involved with research and related duties was low for PEMTEs in Ohio. Time commitments ranged from $0 \%$ to $33 \%$ of professional duty time. This was a larger range than was noted by Eckert and Williams (1972) in their study across faculties ( $0 \%$ to $23.3 \%$ ) or by the Carnegie Foundation (1985), in which a range of $3.2 \%$ to $18.4 \%$ was reported, also across disciplines.

The actual amount of time involved with research and related duties was reported as less than $10 \%$ of professional time for $90 \%$ of the subjects in Ohio. This finding corresponds closely with previous work done on physical education faculty members. Metzler and Freedman (1985) reported that only $9 \%$ of their sample spent more than $10 \%$ of their time with research, and Scott (1986) noted that $90.7 \%$ of his subjects spent less than $20 \%$ of their time so involved. There were no statistically significant differences with regard to active involvement with research on the basis of age $(F=.753, p=.5629)$, gender $(F=.006, p=.9402)$, institution type $(F=2.103, p=.089)$, or $\operatorname{rank}(F=1.463, p .2276){ }^{9}$

PEMTEs are comparable to other physical educators, to other education professors, and to other university professors with regard to research behaviors: A few dominate the many. In contrast to the common perception about university professors, none of these groups are, as a whole, committed to the systematic collection of information as a strategy for questioning, informing, or guiding their professional practice.

\section{Conclusions and Implications}

The focus of this study was on the extent to which PEMTEs in Ohio demonstrate knowledge-acquisition behaviors consistent with their role as members of the university professoriate. The model of the ideal university professor who seeks research-based knowledge by doing research, reading professional journals, and attending professional conferences was used as the guide for this investigation. Paradoxically, the PEMTEs did not perform in ways consistent with this ideal, nor were they discernibly different from other members of 
the professoriate. It would appear that the model for knowledge production, acquisition, and utilization for university professors in general, and for PEMTEs in particular, warrants reconceptualization. The following eight implications from the findings of this study may help in such a reconceptualization.

The first implication is related to identifying and targeting the desired audience for research findings. If researchers want their work to have an impact on the profession, they need to consider the outlets that they choose for publication. If impact upon practice in the schools, colleges, and universities is espoused, then the desired audience of practitioners must be reached. With regard to publishing the results and implications of research, this may mean pursuing publication in journals such as JOPERD and state-level magazines.

A second and related implication is tied to the reward structure in colleges and universities. Faculty who publish in the types of journals just mentioned are rarely rewarded. Such rewards are generally tied to publication prowess (publication in magazines with high rejection rates) rather than any applied measure of professional impact, per se. In some cases, numbers of citations are used as a measure of quality (Creswell, 1985), which would indicate impact of a sort. Whether or not this is impact at a programmatic level or simply a way for researchers to stimulate each other, however, is a question that warrants attention (cf. Sykes, 1988).

A third implication of the findings related to journal reading is that if PEMTEs show no commitment to reading about broad issues in education, their charges are unlikely to show this commitment. Furthermore, the extent to which many undergraduates are aware of pedagogical issues in their own work is questionable.

A fourth implication is related to the practice of future PEMTEs. Today's PEMTEs were once undergraduates in the process of developing their own subjective warrant for the practice of a physical education methods teacher educator. The behaviors that PEMTEs modeled to their students probably influenced the new cadres of PEMTEs who were as yet undergraduates. Put differently, the practice of ignoring the knowledge base in the education literature is most likely to continue. One wonders about the extent to which PEMTEs address or are even aware of issues surrounding their own practice of preparing aspiring teachers.

The fifth implication arises from the extent to which PEMTEs write for publication. Much valuable experience is not shared. Many PEMTEs work in isolation and neither share their own expertise through publication nor benefit from the experience of others who have faced similar obstacles in their professional lives and have written about the experience. The result, to use a worn metaphor, is that the wheel must continually be reinvented.

The data on attendance at professional meetings point to a most promising implication. Because PEMTEs attend state and national meetings with morethan-average regularity, researchers who disseminate the results of their work at such venues have a better chance of reaching these practitioners. Also, if PEMTEs are to be convinced that attending professional meetings on a regular basis is worthwhile, their attendance must be rewarded through stimulating presentations of information they perceive to be relevant. A potentially fruitful line of inquiry involves identifying the information they would deem relevant. Champion (1984) provided some initial insight into the characteristics of research that education 
faculty find useful. Subjects in that study tended to mention "kinds of studies rather than particular investigations" (Champion, 1984, p. 11) and to identify work involving "big names" (such as Piaget, Flanders, Skinner, or Bloom).

The last two implications stem from the low level of involvement with research described in this study. One implication is that PEMTEs model a disregard for the potential for research to inform their work. Such modeling is at odds with an espoused belief that research has a valuable contribution to make to professional practice (Mitchell, 1988). This appears to be yet one more example of the "Don't do as I do, do as I say" approach to teacher education. Surely, the credibility of practitioners with such a philosophy must be taxed.

The other implication involves the study of professional preparation of physical education teachers. If PEMTEs are not interested in studying what they do, there is only a small possibility that anyone else will value their work enough to study it. Raths (1985) found something similar with a sample of education professors: Only $21 \%$ of those involved with teacher education were involved with research in their field (p. 14). The basis for practice, therefore, is most likely to be in the individual experience of those involved in the delivery of service-as shaped by the institutions in which the PEMTEs work. The hope for the development of any shared technical culture (cf. Lortie, 1975) for physical education teacher education is dismal in light of this approach to practice. Furthermore, there is a low probability for the reconceptualization of the ways knowledge is created, utilized, disseminated, and/or valued by PEMTEs. For, unquestionably, more study is required to determine what knowledge is and should be valued; how that knowledge is and should be acquired, utilized, and disseminated; ${ }^{10}$ and what the implications of these strategies are for the quality of service offered by the profession.

\section{References}

Burch, B.G. (1989). Perceptions of the role and scholarly reputation of the education professoriate. In R. Wisniewski \& E.R. Ducharme (Eds.), The professors of teaching: An inquiry (pp. 87-104). Albany, NY: State University of New York Press.

Carnegie Foundation for the Advancement of Teaching. (1976). A classification of institutions of higher education (rev. ed.). Berkeley, CA: Carnegie Council on Policy Studies in Higher Education.

Carnegie Foundation for the Advancement of Teaching. (1985). The faculty: Deeply troubled. Change, 17(4), 31-34.

Champion, R.H. (1984). Faculty reported use of research in teacher preparation courses: Six instructional scenarios. Journal of Teacher Education, 35(5), 9-12.

Creswell, J.W. (1985). Faculty research performance: Lessons from the sciences and the social sciences (ASHE-ERIC Higher Education Report No. 4). Washington, DC: Clearinghouse on Higher Education.

Ducharme, E.R., \& Agne, R.M. (1982). The education professorate: A research-based perspective. Journal of Teacher Education, 33(6), 30-36.

Earls, N.F. (1981). Distinctive teachers' personal qualities, perceptions of teacher education and the realities of teaching. Journal of Teaching in Physical Education, 1(1), 5970.

Eckert, R., \& Williams, H. (1972). College faculty view themselves and their jobs. Minneapolis: The University of Minnesota. 
Feiman-Nemser, S., \& Floden, R. (1986). The cultures of teaching. In M. Wittrock (Ed.), Handbook of research on teaching (pp. 505-526). New York: Macmillan.

Freeman, B.C. (1977). Faculty women in the American university: Up the down staircase. In P.G. Altbach (Ed.), Comparative perspectives on the academic profession (pp. 160-190). New York: Praeger.

Haberman, M. (1981). The influence of selected societal, university, and school conditions on the preparation of the practice of teachers. (ERIC Document Reproduction Service No. ED 207 962)

Huck S.W., Cormier, W.H., \& Bounds, W.G. (1974). Reading statistics and research. New York: Harper \& Row.

Jacobson, R.L. (1985). New Carnegie data show faculty members uneasy about the state of academe and their own careers. Chronicle of Higher Education, 31(16), 1, 2428.

Ladd, E.C., \& Lipset, S.M. (1976). Nearly all professors are satisfied with their choice of an academic career. Chronicle of Higher Education, 12(10), 11.

Lortie, D.C. (1975). Schoolteacher. Chicago: The University of Chicago Press.

Metzler, M.W., \& Freedman, M.S. (1985). Here's looking at you PETE: A profile of physical education teacher education faculty. Journal of Teaching in Physical Education, 4, 123-133.

Minium, E. (1978). Statistical reasoning in psychology and education. New York: John Wiley \& Sons.

Mitchell, M.F. (1988). Perceptions and preferences of physical education methods teacher educators in Ohio. Unpublished doctoral dissertation, The Ohio State University, Columbus.

Park, R.J. (1980). The Research Quarterly and its antecedents. Research Quarterly for Exercise \& Sport, 51(1), 1-22.

Raths, J. (1985, April). Scholarly activities of teacher educators. Paper presented at the annual meetings of the AERA (69th), Chicago. (ERIC No. 257 793)

Rein, M., \& White, S. (1981). Knowledge for practice. Social Service Review, 55(1), 141.

Scott, M.W. (1986). A study to profile the features of physical educators in higher education by institutional level. Unpublished doctoral dissertation, The University of North Carolina at Greensboro.

Silverman, S. (1987). Trends and analysis of research on teaching in doctoral programs. Journal of Teaching in Physical Education, 7, 61-70.

Sykes, C.J. (1988). ProfScam: Professors and the demise of higher education. New York: St. Martin's Press.

Williamson, K.M. (1990). The ivory tower: Myth or reality? Journal of Teaching in Physical Education, 9, 95-105.

Wisniewski, R., \& Ducharme, E.R. (1989). Where we stand. In R. Wisniewski \& E.R. Ducharme (Eds.), The professors of teaching: An inquiry (pp. 147-162). Albany, NY: State University of New York Press.

\section{Notes}

${ }^{1}$ Two irregularities were noted in the selection of the sample. One subject refused to participate. An alternate subject of the same gender from the same institution was 
selected. Another subject had left the state for the entire period of data collection and could not be reached. An alternate subject of the same gender was selected from the same institution.

${ }^{2}$ The category of "other'" was included to catch any duties not covered as part of the classic responsibilities of teaching, research, service, and, for physical education faculty, coaching. For several subjects, this category was identified as administrative duties.

${ }^{3}$ Strategies did not exist at the time of the Metzler and Freedman (1985) study.

${ }^{4}$ There is the possibility that a Type I error occurred. Huck, Cormier, and Bounds (1974) identified a Type I error as "rejecting the null hypothesis when it should be accepted"' (p. 45).

${ }^{5}$ There is the possibility that a Type I error occurred.

${ }^{6}$ There is the possibility that a Type II error occurred. Huck, Cormier, and Bounds (1974) identified a Type II error as "'accepting the null hypothesis when it should be rejected"' (p. 45).

${ }^{7}$ There is the possibility that a Type II error occurred.

${ }^{8}$ There is the possibility that a Type II error occurred.

${ }^{9}$ There is the possibility that a Type II error occurred.

${ }^{10}$ Park (1980) provided an interesting account of the history of AAHPERD's attempts to meet the needs of the membership in this regard.

\section{Acknowledgment}

An earlier version of this paper was presented at the National Convention of AAHPERD in New Orleans, March 31, 1990. 